\title{
A pilot study that provides evidence of epigenetic changes among mother-child pairs living proximal to mining in the US
}

\author{
Guoshuai Cai $\cdot$ Xuanxuan Yu $\cdot$ David Hutchins $\cdot$ \\ Suzanne McDermott $(\mathbb{D}$
}

Received: 2 November 2021 / Accepted: 27 January 2022 / Published online: 8 February 2022

(C) The Author(s), under exclusive licence to Springer Nature B.V. 2022, corrected publication 2022

\begin{abstract}
Environmental exposures to chemicals can disrupt gene expression, and the effects could be mediated by methylation. This investigation focused on methylation of genes associated with exposure to metals. Mother-child pairs from three locations in Montana were recruited, and buccal cells were collected for genome-wide methylation assay. Four pairs were from Butte, where there is mining and a Superfund site, four pairs were from Anaconda with a Superfund site, and four pairs were from Missoula with neither a mine nor a Superfund site. Principal component analysis, linear mixed models,
\end{abstract}

Supplementary Information The online version contains supplementary material available at https://doi. org/10.1007/s10653-022-01217-9.

\section{G. Cai}

Department of Environmental Health Sciences, Arnold School of Public Health, University of South Carolina, Columbia, SC, USA

\section{Yu $\cdot$ D. Hutchins}

Department of Epidemiology and Biostatistics, Arnold School of Public Health, University of South Carolina, Columbia, SC, USA

D. Hutchins

Montana Technological University, Butte, MT, USA

S. McDermott ( $\square)$

Department of Environmental, Occupational, and Geospatial Health Sciences, CUNY Graduate School of Public Health \& Health Policy, New York, NY, USA e-mail: suzanne.mcdermott@sph.cuny.edu hierarchical clustering and heatmap, and gene set enrichment analysis were used to visualize the profiles, identify the top associated methylation loci, and investigate the involved pathways. Distinctly higher or lower methylation in samples from Butte were found at the top differentially methylated loci. The 200 genes harboring the most hypermethylated loci were significantly enriched in genes involved in actin cytoskeleton regulation, $\mathrm{ABC}$ transporters, leukocyte transendothelial migration, focal adhesion, and adherens junction, which plays a role in pathogenesis of disease, including autism spectrum disorders. This study lays a foundation for inquiry about genetic changes associated with environmental exposure to metals for people living in proximity to Superfund and open pit mining.

Keywords Mining - Superfund · Buccal · Methylation · Principal component analysis · Molybdenum $\cdot$ Copper $\cdot$ Heatmap

A substantial evidence base, particularly from in vivo toxicology studies, has demonstrated a causal relationship between metal combinations on human health. Ex vivo studies have shown that high concentrations of metal mixtures are associated with cognitive impacts in the mammalian brain, including mercury $(\mathrm{Hg})$, arsenic $(\mathrm{As})$, cadmium $(\mathrm{Cd})$, lead $(\mathrm{Pb})$, and manganese (Mn) (Andrade \& Aschner, 2017; Andrade et al., 2015; Cobbina et al., 2015; Rai et al., 
2010). The mechanisms of action have been demonstrated through oxidative stress, inhibition of acetylcholine esterase, and effects on the nervous system and impacts on the hematopoietic system (Lin et al., 2016). Exposure science has been focusing on metal mixtures and other environmental factors and assessing their impact on human health outcomes (NIEHS, 2021). This investigation focused on one type of biologic change in genes that is associated with exposure to at least six metals [copper $(\mathrm{Cu})$, molybdenum (Mo), arsenic (As), manganese $(\mathrm{Mn})$, lead $(\mathrm{Pb})$, and zinc $(\mathrm{Zn})]$ in the air and soil, associated with mining.

Epigenetics, the heritable gene expression changes without altering the DNA sequence, plays essential roles in genomic imprinting, embryonic cell differentiation, postnatal development, and aging (Avgustinova \& Benitah, 2016; Ferguson-Smith, 2011; Lessing et al., 2013; Lin et al., 2016; Lunyak \& Rosenfeld, 2008; NIEHS, 2021). As one of the major epigenetic mechanisms, methylation of DNA is caused by the addition of a methyl $(\mathrm{CH} 3)$ group at the carbon 5 position in the sequence 5 ' $\mathrm{CpG} 3$ ' to the cytosine ring, activated by the enzyme DNA methyltransferase. Methylation plays a vital role in regulating gene expression, as hypermethylation inactivate gene expression can block the bond of the transcriptional or repressor factors to their recognition sites (Razin \& Cedar, 1991). Studies have shown that environmental exposures (such as to arsenic or cadmium) can disrupt gene expression, and the effects could be mediated at least partially by methylation (Andrew et al., 2008; Arita \& Costa, 2009; Reichard \& Puga, 2010). Importantly, both inactive and active epigenetic states of genes are inherited (Heard \& Martienssen, 2014; Skvortsova et al., 2018). It is emerging that metals' neurotoxicity can have dramatic consequences that can last a lifetime through epigenetic dysregulation (Cardenas et al., 2017; Senut et al., 2012). These consequences could affect future generations. Extensive animal models augment this premise (Skinner et al., 2013; Vassoler et al., 2014; Wolff et al., 1998).

Active mine sites and historic mining, including Superfund areas, are the nation's most contaminated areas for metals. The residents of Butte Montana, in Silver Bow County have exposure to active copper and molybdenum mining occurring at an extremely large open pit, located just northeast of the town of Butte. Mining for copper ( $\mathrm{Cu}$ ) and molybdenum (Mo) has been ongoing for the past twenty years, with As,
$\mathrm{Mn}, \mathrm{Pb}$, and zinc ( $\mathrm{Zn})$ also extracted as part of the process (Andrade \& Aschner, 2017) Butte residents are also exposed to numerous underground historic mining sites, including the Silver Bow Creek/Butte Superfund Area (EPA, 2020; Schecher \& McAvoy, 1992), which are proximal to the mine and the town of Butte. It is unknown to what degree the mine adds to or separately contributes to human health dangers, over and above exposures from the historic sites. This study focused on the biologic differences among mother child pairs, by comparing the methylation sites in mother-child pairs living in Butte and potentially exposed to pollution from active and historic mining, compared to mother child pairs who live in Anaconda where there is no active mining but there is a large historic smelting operation that is a Superfund site, and to mother-child pairs from Missoula, over 100 miles west of Butte and Anaconda, where there is no active or historic mining.

\section{Method}

Human subject considerations

This study received Expedited review, based on Categories 3 and 7, and it was approved by the University of South Carolina Institutional Review Board, where the data analysis occurred. The study recruiter discussed the study with the mother in each family unit. The mother then read and signed an informed consent form that explained the study purpose and protocol, and informed that family that the mother would receive a $\$ 20$ gift card and the child would receive a $\$ 10$ gift card. Participating children over the age of 5 years were read an assent script that summarized the purpose and the protocol.

\section{Recruitment}

The Montana-based recruiter identified and recruited mother-child pairs from three Montana towns. There were four pairs from Butte, four pairs from Anaconda, and four pairs from Missoula. This was a convenience sample, and the recruitment was conducted through personal contacts, flyers posted at appropriate venues, social media announcements, and at community gathering areas and events. The target population was children and their mothers who reside in either Butte, 
Anaconda, or Missoula, Montana. We included some children who have been placed in special education and others who were in regular education classes. The children were ages 4-11 years. We did not discriminate by race or ethnicity, but as expected, most were Caucasian, like almost $90 \%$ of the population of Montana. We collected a buccal sample from the mother of each child, with whom the child resided. The exclusion criteria were families who have moved to Anaconda or Butte or Missoula after the child was born and/or children who have a known genetic condition, such as Down's syndrome or Fragile X syndrome. Mothers read and sign an informed consent document that clearly explained the study along with potential risks.

\section{Data collection}

For each mother-child pair, we collected the following:

1. Maternal survey, which included information about where the child lived from the time that the child was in utero to the current time, as well as the child's school placement and some limited health information.

2. Buccal sample from mother and child.

The procedures that we used to collect the buccal cells are the standard sample collection procedures provided by the manufacturer of the swab kits, ORAcollect. We utilized their OCD-100/OCD-100A swab kit for the adult participants and the OC-175 swab kit for the child participants, as is recommended. Prior to buccal cell collection, the subjects were advised to rinse their mouth thoroughly with water to remove unwanted debris. Exfoliated buccal cells were obtained from the mother by gently rubbing the inside of both cheeks with a soft foam brush for one minute each. The brush was then placed in the collection tube, and the preservative was added. For the child, buccal cells were collected by saturation of a foam brush with saliva, and the brush was compressed to force the sample into a collection tube. The process is repeated until an adequate sample was collected, and then the preservative was added. The entire collection process took between 5 and $10 \mathrm{~min}$.
The tubes containing the buccal cell samples were shipped in one batch to a commercial laboratory for DNA extraction and assessment of methylation. DNA from buccal samples was extracted and measured by AKESOgen, Inc., GA. Picogreen assay (Invitrogen ${ }^{\mathrm{TM}}$, Life Technologies Corporation, NY) and Bioanalyzer assay (Agilent Technologies, Inc. CA) were used to control DNA quality. Methylation levels of more than 850,000 methylation sites were measured using the Human Infinium MethylationEPIC BeadChip (Illumina, Inc. CA).

\section{Data processing and analysis}

We used the R package minfi (Fortin et al., 2017) to perform methylation data processing, including probe annotation by mapping probes to genome using the Illumina human methylation EPI Canno.ilm10b4. hg $19 \mathrm{R}$ package, quality control including removing large detection $p$-values $(>0.01)$, background correction by thresholding probes with values smaller than -3 of standard deviation from the median in $\log 2$ scale, followed by subset-quantile within array normalization where probes are stratified by region $(\mathrm{CpG}$ island, shore, etc.). Given that common SNPs may affect the methylation measurement, we removed sites from analysis if they contain SNPs at the $\mathrm{CpG}$ interrogation or at the single nucleotide extension. For each probe, Beta and $\mathrm{M}$ values were calculated for methylation level quantification. Specifically, for probe $i$ with methylation signal $\gamma_{i, \text { meth }}$ and unmethylation signal $\gamma_{i, \text { unmeth }}, M_{i}=\log _{2}\left(\frac{\max \left(\gamma_{i, \text { meth }}, 0\right)+1}{\max \left(\gamma_{i, \text { unmeth }}, 0\right)+1}\right)$ and $\operatorname{beta}_{i}=\frac{\max \left(\gamma_{i \text { meth }}, 0\right)}{\max \left(\gamma_{i, \text { meth }}, 0\right)+\max \left(\gamma_{i, \text { ummeth }}, 0\right)+1}$.

To investigate the overall patterns inherited in samples, principal component analysis (PCA) was conducted on the centered and scaled $\mathrm{M}$ values of all probes. Patterns were visualized in the PCA plot of the first three principal components. Further, for each mapped probe, we compared samples from Butte to those in Anaconda and Missoula on $\mathrm{M}$ values, which are more statistically valid in linear model-based differential analyses than beta values (Du et al., 2010). To account for group random effects from family and site, a linear mixed model also fitted as

$M_{i}=\beta_{i 0}+\beta_{i 1} *$ Butte $_{j}+\beta_{i 2} *$ mom $_{j}+\alpha_{i 1} *$ family $_{j}+\alpha_{i 2} *$ town $_{j}+e_{i j}$ 
where $i$ denotes probe, $j$ denotes sample, Butte $_{j}=1$ for samples from Butte and 0 for other regions. $\operatorname{mom}_{j}=1$ for moms and 0 for children. family ${ }_{j}$ and town $_{j}$ encode which family and town sample $j$ comes from. $\beta_{i 0}, \beta_{i 1}, \beta_{i 2}$ are fixed effects, $\alpha_{i 1}, \alpha_{i 2}$ are random effects where $\alpha_{i 1} \sim N\left(0, \sigma_{i 1}^{2}\right), \alpha_{i 2} \sim N\left(0, \sigma_{i 2}^{2}\right)$ and $e_{\mathrm{ij}}$ is residual and $e_{\mathrm{ij}} \sim N\left(0, \sigma_{\mathrm{ie}}^{2}\right)$. Differential methylation patterns were identified between the study groups: (1) Butte versus the other two sites; and (2) mothers versus children. Further, hierarchical clustering and heatmap were used to visualize the profiles (beta values, the percentage of methylated molecules) of top 50 differential methylation probes of known genes in samples. Note that the beta values were scaled and centered for each methylation probe. Also, gene set enrichment analysis (GSEA) via MSigDB (Liberzon et al., 2011) was performed to explore the involved biological pathways and functions. The enrichment of 200 genes which has top differentially methylated loci in the Hallmark and KEGG gene sets was assessed, and significantly enriched gene sets were identified with $q$-value $<0.05$.

Collection of reported autism spectrum disorders (ASD)-associated genes

The ASD-associated genes identified from 42 genome-wide association (GWAS) studies were obtained from GWAS Catalog (Buniello et al., 2019) (trait label: autism spectrum disorder; trait ID: EFO_0003756). ASD-associated genes were also obtained from MalaCards (Rappaport et al., 2017), which inferred gene-disease connections by integrating 73 data sources.

\section{Results and discussion}

Demographic differences between sites

We were able to get buccal samples from 23 individuals. There were eleven maternal-child pairs (22 individuals) and one child (maternal sample was not available). The characteristics of the mother-child pairs are shown in the top part of Table 1. The age and grade level of the children, and the residences since birth, are not substantially different in the three locations. The medical and educational diagnoses provided by the mothers all suggest neurodevelopmental differences in $50 \%$ of the children who participated in the study. Two of the four children from Butte, one of the four children from Anaconda, and three of the four children from Missoula had a neurodevelopmental diagnosis.

We also gathered data from two publicly available datasets. In the second section of Table 1, the first three rows show the 2010 US Census data for the three Montana counties. We used the 2010 census data to compare the three counties: Silver Bow county (including Butte), Deer Lodge county (including Anaconda), and Missoula county (including Missoula) since the Behavioral Risk Factor Surveillance System (BRFSS) data shown in the lower part of Table 1 represent data from 2009 for Butte and 2012 for Missoula. The three towns are very different in terms of population but their age and race distributions are similar. The BRFSS data, shown in the final section of Table 1, are based on self-report on a nationally standard telephone survey. The Montana BRFSS aggregated data for Standard Metropolitan Statistical Areas (SMSA) and since Anaconda has such a small population, it is not a SMSA, and therefore, these data are not available. The behavioral risk factors selected are shown for Butte SMSA and Missoula SMSA in Table 1. They are similar for alcohol use, smoking, overall health, and chronic disease.

Physical location of the three sites

A map of western Montana is shown in Fig. 1. The map shows the location of the three cities: Butte (in Silver Bow county), Anaconda, (in Deer Lodge county), and Missoula (in Missoula county). As observed, Missoula is approximately 100 miles to the west of Anaconda and Butte in far western Montana.

Mother-child differences in methylation

For each sample, methylated and unmethylated signals of $1,051,815$ probes were acquired, in which 865,859 probes were mapped to the hg19 genome. After filtering probes with large detection $p$-values and background correction, 861,890 probes were kept. Further, 29,360 probes in the SNP site were removed, and $\mathrm{M}$ values and beta values of 832,530 probes were retained for downstream analysis.

Principal components analysis was performed on $\mathrm{M}$ values, and the top one PC (PC1) clearly 
Table 1 Maternal responses to survey administered for the Montana metals exposure study ( $n=12$ mothers) and community characteristics where the mother-child pairs resided

\begin{tabular}{|c|c|c|c|}
\hline & Butte families $(n=4)$ & Anaconda families $(n=4)$ & Missoula families $(n=4)$ \\
\hline Child's age at assessment & $8-10$ years & $8-11$ years & $4-11$ years \\
\hline $\begin{array}{l}\text { Child's last grade completed at time } \\
\text { assessment (which occurred in } \\
\text { summer) }\end{array}$ & First to third & Fourth and fifth (one was left blank) & Pre-school to $5^{\text {th }}$ grade \\
\hline Number in special education & 2 & 1 & 3 \\
\hline Medical or educational diagnoses & Low IQ; Autism & Sensory processing disorder & $\begin{array}{l}\text { Cognitive delay; ADHD and } \\
\text { dyslexia; Oppositional defi- } \\
\text { ant disorder and ADHD }\end{array}$ \\
\hline $\begin{array}{l}\text { COVID signs and symptoms on day } \\
\text { of buccal cell collection* }\end{array}$ & 0 & 0 & 0 \\
\hline $\begin{array}{l}\text { Number of residences since child's } \\
\text { birth }\end{array}$ & 2 to 3 & 1 to 3 & 1 to 3 \\
\hline $\begin{array}{l}\text { Number of these residences since } \\
\text { child's birth in the same town as } \\
\text { current residence }\end{array}$ & All in Butte & All in Anaconda & 2 \\
\hline
\end{tabular}

Community characteristics-2010 census data (2010) for three county characteristics, and behavioral risk factor surveillance system (BRFSS) for Missoula metropolitan statistical area (2012) and Butte-silver bow county metropolitan statistical area (SMSA) $(2009)^{* *}$

\begin{tabular}{|c|c|c|c|}
\hline \multicolumn{4}{|l|}{ US census data } \\
\hline County population & 35,133 & 9,421 & 117,922 \\
\hline County age $>18$ years & $80 \%$ & $83 \%$ & $80.6 \%$ \\
\hline County race-white only & $92.1 \%$ & $91.6 \%$ & $91.0 \%$ \\
\hline \multicolumn{4}{|c|}{ Behavioral risk factor surveillance system (BRFSS) data for two standard metropolitan statistical areas } \\
\hline \multicolumn{4}{|l|}{ Alcohol use } \\
\hline At least one drink in the last 30 days & $54.8 \%$ & n.a. ${ }^{\mathrm{a}}$ & $64.5 \%$ \\
\hline $\begin{array}{l}\text { Heavy drinking (men }>2 \text { drinks/day, } \\
\text { women }>1 \text { drink/day) }\end{array}$ & $6.1 \%$ & n.a. ${ }^{a}$ & $8.1 \%$ \\
\hline $\begin{array}{l}\text { Binge drinking (men } \geq 5 \text { drinks, } \\
\text { women } \geq 4 \text { drinks) }\end{array}$ & $23.2 \%$ & n.a. ${ }^{a}$ & $27.5 \%$ \\
\hline \multicolumn{4}{|l|}{ Smoking } \\
\hline Current & $22.7 \%$ & n.a. ${ }^{\mathrm{a}}$ & $20.0 \%$ \\
\hline \multicolumn{4}{|l|}{ Smoking status } \\
\hline Everyday & $19.1 \%$ & n.a. ${ }^{a}$ & $13.7 \%$ \\
\hline Some days & $3.7 \%$ & n.a. ${ }^{\mathrm{a}}$ & $6.3 \%$ \\
\hline Former smoker & $24.9 \%$ & n.a. ${ }^{a}$ & $25.4 \%$ \\
\hline Never smoker & $52.3 \%$ & n.a. ${ }^{\mathrm{a}}$ & $54.6 \%$ \\
\hline \multicolumn{4}{|l|}{ Overall health } \\
\hline Excellent & $15.2 \%$ & n.a. ${ }^{a}$ & $23.2 \%$ \\
\hline Very Good & $32.5 \%$ & n.a. ${ }^{\mathrm{a}}$ & $35.5 \%$ \\
\hline Good & $33.3 \%$ & n.a. ${ }^{a}$ & $28.6 \%$ \\
\hline Fair & $14.6 \%$ & n.a. ${ }^{a}$ & $9.1 \%$ \\
\hline Poor & $4.4 \%$ & n.a. ${ }^{a}$ & $3.7 \%$ \\
\hline \multicolumn{4}{|c|}{ Chronic disease indicator - cardiovascular disease } \\
\hline $\begin{array}{l}\text { Ever told you had angina or coronary } \\
\text { heart disease }\end{array}$ & $2.9 \%$ & n.a. ${ }^{a}$ & $2.3 \%$ \\
\hline
\end{tabular}


Table 1 (continued)

Behavioral risk factor surveillance system (BRFSS) data for two standard metropolitan statistical areas

\begin{tabular}{lll}
$\begin{array}{l}\text { Ever told you had a heart attack (myocar- } \\
\text { dial infarction) }\end{array}$ & $5.7 \%$ & n.a. ${ }^{\text {a }}$ \\
$\begin{array}{lll}\text { Ever told you had a stroke } & 1.9 \% & \text { n.a. }{ }^{\text {a }}\end{array}$ \\
\hline
\end{tabular}

*No COVID symptoms were endorsed; however, if any answers were positive for COVID-19 (e.g., cough, fever), they were not included as a participant

**The BRFSS did not aggregate Anaconda-Deer Lodge County data since it is not a SMSA. BRFSS data for Missoula and Butte are for different years based on available BRFSS data

${ }^{a}$ n.a. not available since Anaconda is not a SMSA

\section{Map of Montana: Cities of Butte, Anaconda and Butte}
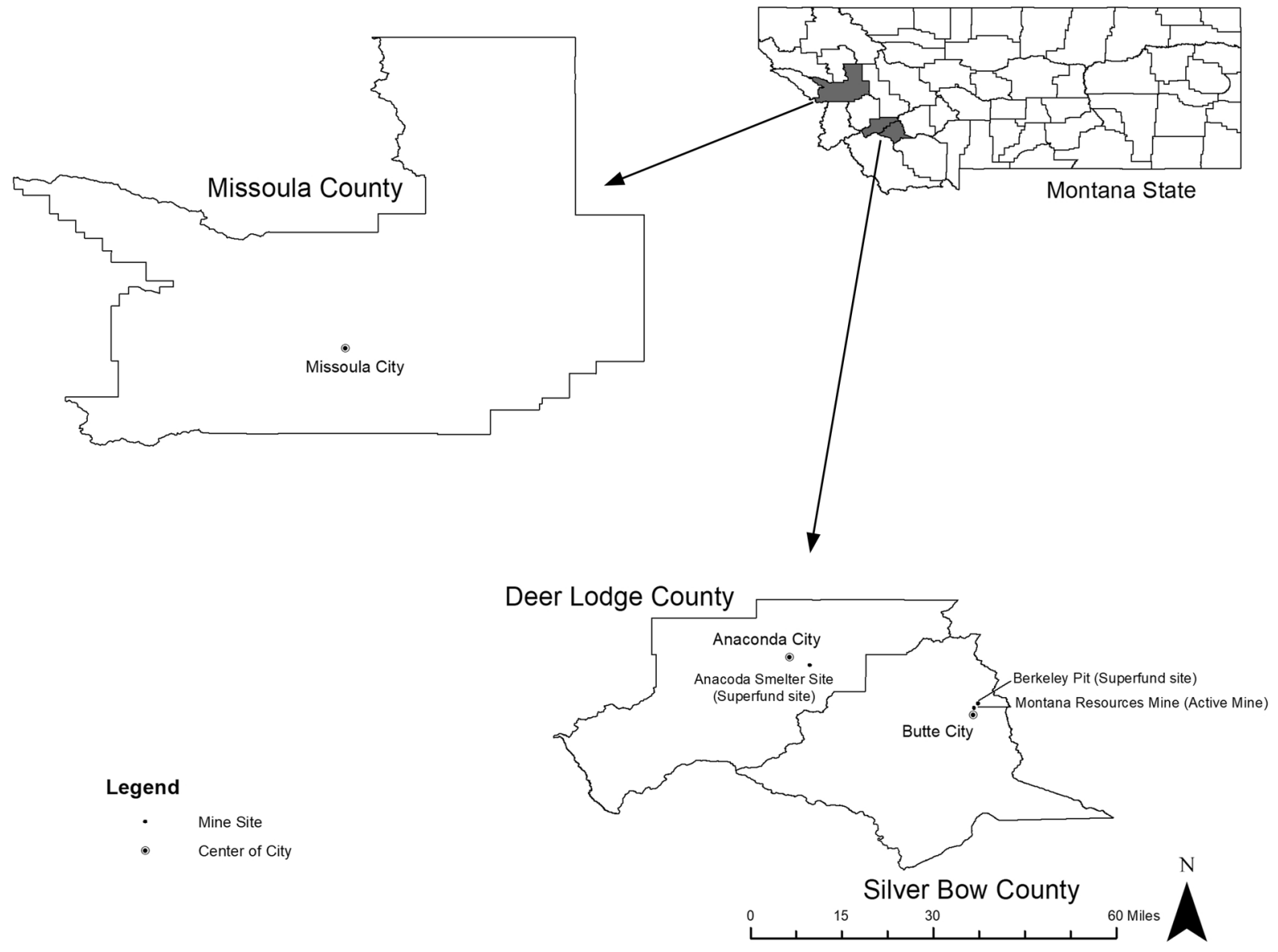

Fig. 1 Map of Montana: cities of Butte, Anaconda and Butte

distinguish children from mothers (Fig. 2A, C), which is well-aligned with the knowledge that aging strongly affects methylation. Moreover, the mother-child correlation of $\mathrm{PC} 1$ was observed showing that mothers with high PC1 scores tended to have children with high PC1 scores, reflecting the extensively reported epigenetic inheritance across generations. 

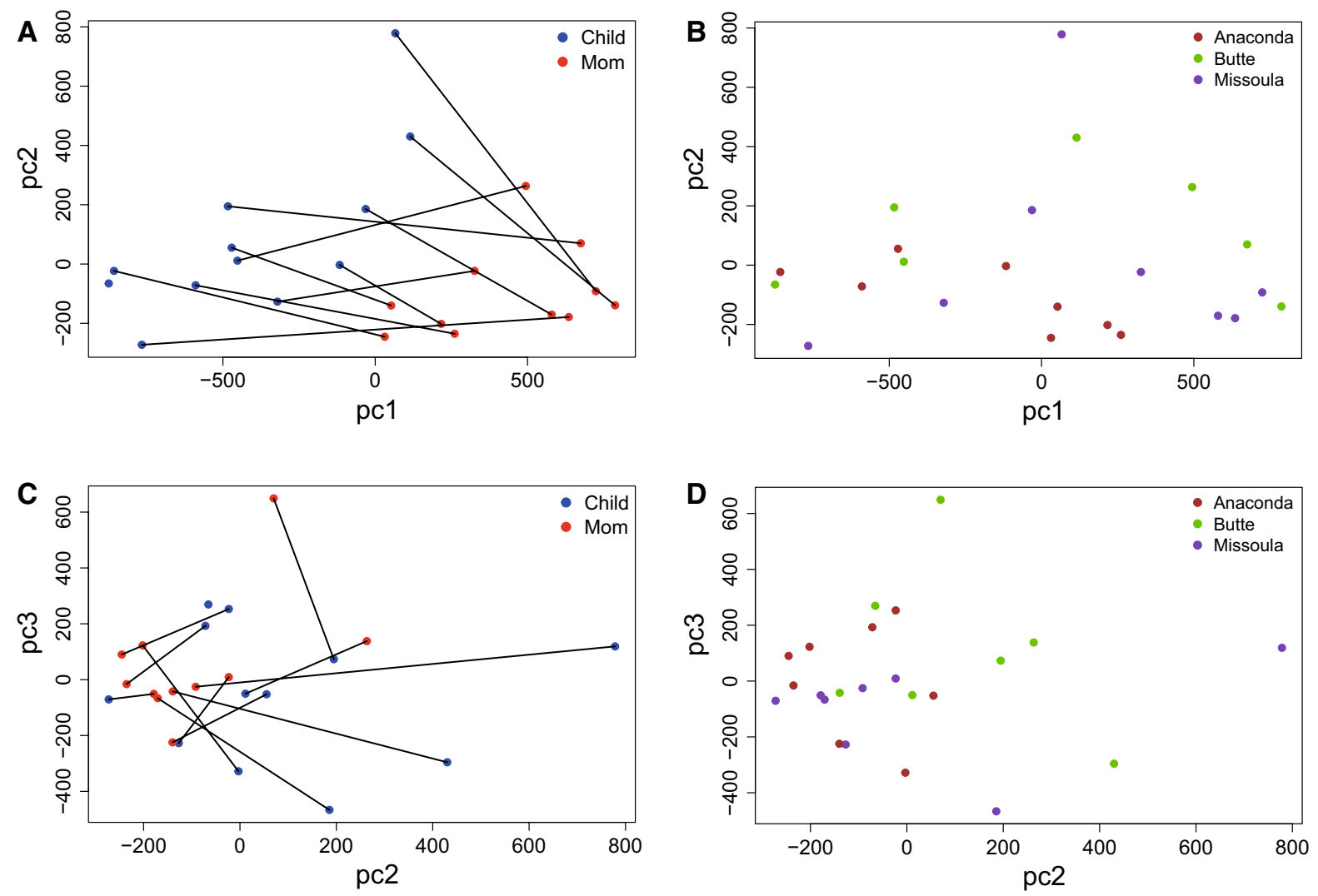

Fig. 2 Principal component analysis of methylation of maternal and child buccal samples, from Butte, Anaconda, and Missoula. Samples were colored by mothers (mom) and children

(Child) in (A, C), or locations in $(\mathbf{B}, \mathbf{D})$. Families were connected by lines in $(\mathbf{A}, \mathbf{C})$

We also compared mothers to children and identified their differentially methylated probes. A distinct methylation pattern was observed between mothers and children from the top 50 differentially methylation loci of known genes (Figure S1A). GSEA analysis found that signaling of KRAS, apical junction, TNF- $\alpha$ via NFkB, and TGF- $\beta$ were upregulated, while UV response-related genes were downregulated (Figure S1B). This may show the underlying mechanism of aging related to the increased risk of uncontrolled cell proliferation and weaken ability of DNA repair and cell apoptosis. Involved in KRAS, TNF- $\alpha$, and TGF- $\beta$ pathways (Figure S1C), ID2 may play a pivotal role in the aging effect via epigenetic change, which warrant further investigation. This observation may link to

the finding of a previous animal study that aging upregulated the expression of ID2 and other apoptosis inhibiting genes, and potentially enhanced the apoptosis resistance of CD8 central memory T cell. (Yang et al., 2021).

\section{Butte differs from Anaconda and Missoula}

This pilot study identified a pattern of DNA methylation that distinguished the mother-child pairs in the Butte area compared to the pairs from Anaconda and Missoula. Interestingly, the second PC (PC2) showed a significant difference between Butte compared to Missoula and Anaconda (two-sided Wilcoxon rank sum exact test, $p$-value $=0.027$, which is shown in 


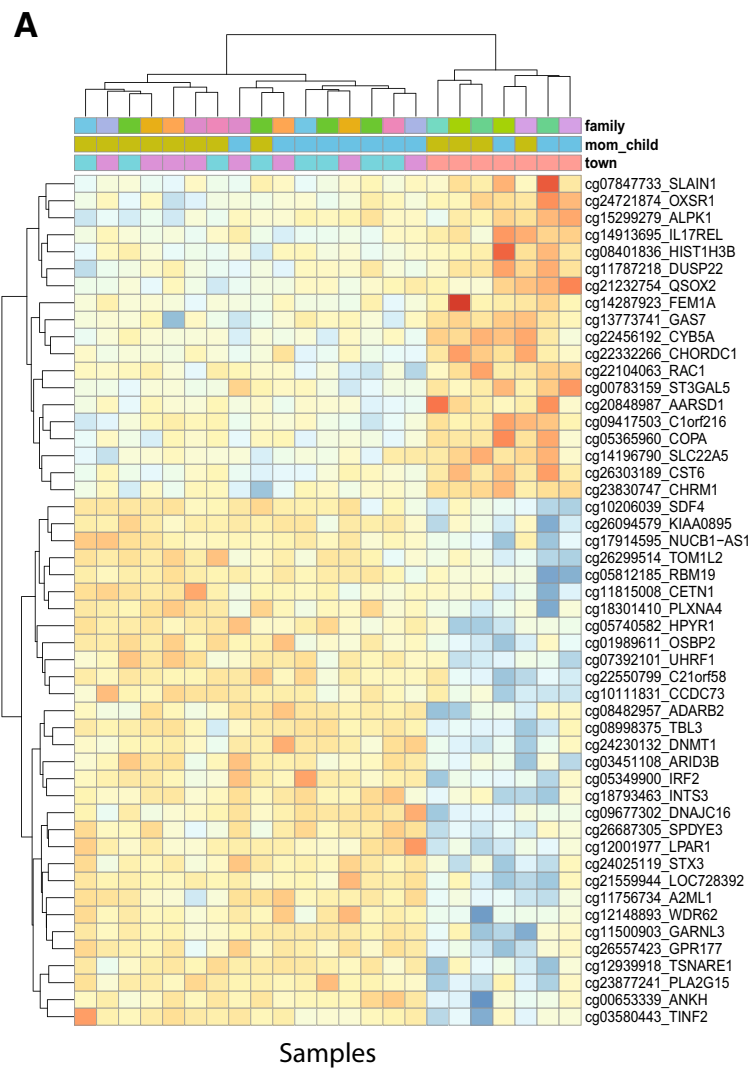

Fig. 3 Differential methylation between samples from Butte and other two sites. A Heatmap of the top 50 differential methylation loci in samples. For each probe, the scale corresponds to the beta value which was centered and scaled. The dendrogram indicates the similarity of the samples. Mothers and chil-

Fig. 2B, D. No significant difference was observed between Anaconda and Missoula samples.

Further, we identified differential methylation between Butte and other sites in all samples by fitting a random effect model described in the Methods section. The top 50 differentially methylated loci of known genes distinctly showed higher or lower methylation in samples from Butte as compared to those from other sites (Fig. 3A). The top 200 genes harboring hypermethylated loci were significantly enriched in pathways of actin cytoskeleton regulation, $\mathrm{ABC}$ transporters, leukocyte transendothelial migration, focal adhesion, and adherens junction (Fig. 3B). Disturbance of these pathways have been reported in ASD pathogenesis studies, (Folmsbee et al., 2016; Griesi-Oliveira et al., 2018; Iritani et al., 2018; Nazeen et al., 2016;
B

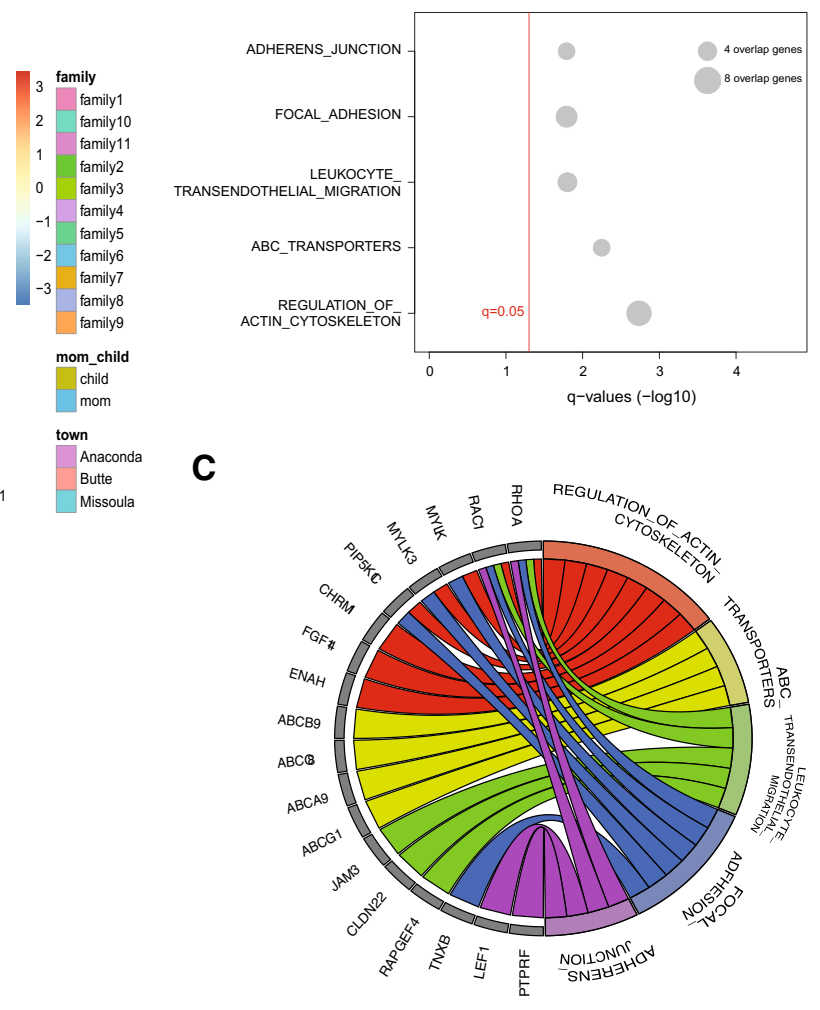

dren, and site are color-coded. B Enriched pathways of genes with the top 200 differential methylation loci. Dot sizes were determined by the number of detected genes involved in each pathway. For each gene, the connection to its involved pathways is illustrated in $(\mathbf{C})$

Onore CE et al., 2012), and thus environmental exposure in Butte may link to ASD through methylation dysregulation. Involved in four of these five pathways (Fig. 3C), ROHA and RACl encodes proteins which play important roles in neural development. RohA is required for neuroblast proliferation (Lee et al., 2000), and Rac1 is essential in axon growth and guidance and in neuronal survival (Hua et al., 2015).

Among the 500 genes which harbors the top differentially methylated loci between Butte and other studied sites, 16 genes showed association with ASD in GWAS studies, and more associated genes $(n=29)$ were identified by integrating multiple lines of evidence (Fig. 4). Three genes (CACNA1C, RIMS1, and $C S M D 1$ ) were found by all these three sources (this study, GWAS studies and multi-evidence integration), 


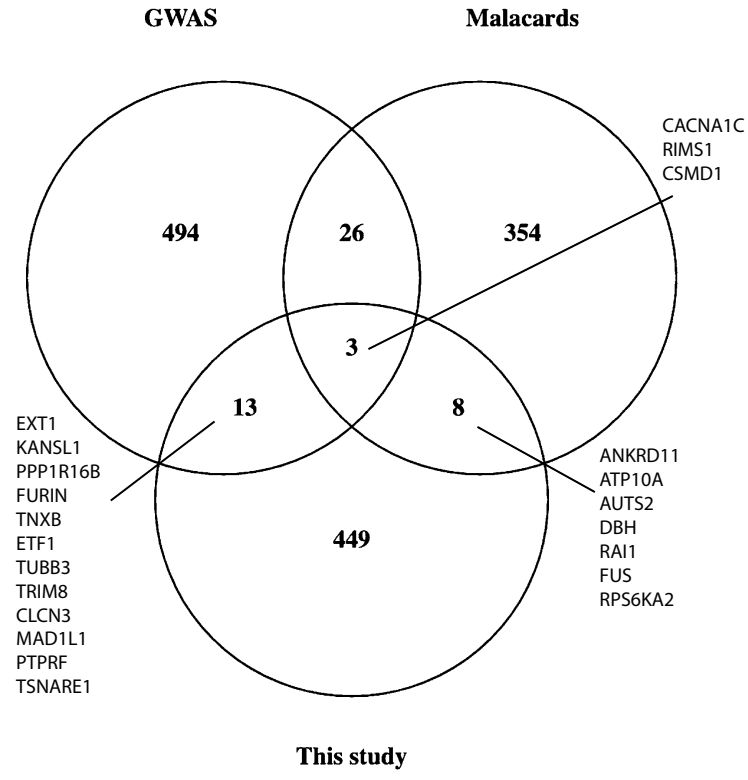

Fig. 4 Overlap of detections between differential methylated genes in this study and ASD-associated genes in GWAS studies and MalaCards

which imply their important roles in mediating the metal toxicity and neurological abnormalities and warrant further experimental and large-scale epidemiological studies. Indeed, studies have shown that exposure to lead (Ferreira de Mattos et al., 2017) or cadmium (Phuapittayalert et al., 2016) affect $C A C$ NAIC expression and Cav1.2 ion channels.

We focused on specific geographic location because of our knowledge of the potential for metal exposures in the three locations. The Butte families are exposed to both historic mining sites and active open-pit mining, the Anaconda families are exposed to historic smelter tailings, and the Missoula families are exposed to neither of these specific metal sources.

\section{Implications of findings}

The anticipated variation in exposure based on geospatial factors allowed us to conduct these analyses. The residents of Anaconda and Butte have lived with the knowledge that there are harmful metals in their environment for over 30 years, and Superfund clean-up is underway. The existence of ongoing open-pit mining for $\mathrm{Cu}$ and $\mathrm{Mo}$, located within one mile of residential Butte (Fig. 1), adds to the exposure for the families living in this area. The citizens of Butte and Anaconda have been informed about the impact on animals and waterways, but there has been limited information about human health effects. Notably, the residents have been told by the Environmental Protection Agency (EPA) that there are only three contaminants of concern-arsenic, lead, and mercury. However, it is established that other neurotoxic metals present, e.g., $\mathrm{Cu}, \mathrm{Mn}, \mathrm{Zn}$, are associated with adverse human health outcomes.

Superfund, abandoned mining sites, and active mining are the nation's most contaminated areas for metals. About 11 million people in the US, including three to four million children, live within $1.5 \mathrm{~km}$ of a federal Superfund site (EPA, 2020). There is evidence that transporting metals from Superfund sites does not reduce environmental concentrations, primarily due to associations with nanoscale mineral phases of iron oxides and mixed titanium/iron oxides (Plathe et al., 2010). Additionally, sediments are enriched above background by a factor of two to five times, even $500 \mathrm{~km}$ away from Superfund sites, (EPA, 2020) indicating that there is exposure to a much broader population.

The residents of Butte Montana have exposure to active copper and molybdenum mining occurring at a large open pit, located just northeast of the town. They are also exposed to the Superfund site, known as the Silver Bow Creek/Butte Area, which is proximal to the mine and town. It is unknown to what degree the mine adds to or separately contributes, to human health dangers, over and above exposures from historic mining and one of the largest Superfund sites in the US. The historically contaminated soils are in close proximity to the operations of the active Montana Resources copper and molybdenum mine in Butte. As a result, Silver Bow Creek, which flows through the town of Butte, has been shown to have contaminated local soils, sediments, ground water, and surface water with numerous metals (Plathe et al., 2010).

The Anaconda residents also live proximal to a Superfund site, in the contiguous county to the northwest of Butte. This Superfund site is a former ore processing facility/smelter. The town of Anaconda includes a number of residential neighborhoods in proximity to two large tailings ponds (the Anaconda Pond and the Opportunity Pond) and the former Anaconda smelter stack. The US Environmental Protection Agency (EPA) added 
the Silver Bow Creek/Butte area and the Anaconda and Opportunity areas to the National Priority List in 1983, designating them as Superfund sites. The EPA lists $\mathrm{As}, \mathrm{Cd}, \mathrm{Pb}$, and $\mathrm{Hg}$ as metal contaminants of concern for residents living near these Superfund sites (USEPA. Silver Bow Creek, Butte Area Butte $\&$ MT Superfund Site., 2020). Figure 1 shows the two Superfund sites and the active mine sites.

Limitations of the study

This pilot study has substantial limitations, most importantly the small sample size for mothers and children that limits the power of our findings. In addition, we were not able to identify risk factors that could have some explanatory value, such as whether the mother or other household member worked in mining, the exact locations of the residences in relation to prevailing winds, and distance to the Superfund sites and open-pit mine. As a result of the small sample size and the inability to geocode the exact mother-child residential locations, the methylation sites that distinguished the Butte families from the others need to be confirmed by a substantially larger study.

\section{Conclusion}

We hope this pilot study will lay a foundation for more scientific inquiry about the biologic changes and health consequences of environmental exposure to heavy metals. This information is needed to understand the impact of metal exposures on biomarkers and the resulting consequences on the health of people living in proximity to both historic and active mining.

\begin{abstract}
Author Contributions GC designed the methylation assay procedure and carries out data analysis for the project with the assistance of his $\mathrm{PhD}$ candidate student $\mathrm{XY}$. DH was the site recruiter and he was responsible for the data collections. SMcD was responsible for the design, execution, and the drafting of the manuscript for the study. All authors contributed to the final version of the manuscript.
\end{abstract}

Funding This study was funded with University of South Carolina Arnold School of Public Health research funds dedicated to preliminary studies by the Corresponding Author. These funds paid for supplies, recruitment costs, and laboratory expenses.
Data Availability The data used for this study are available from reasonable requests from the corresponding author.

\section{Declarations}

Conflict of interest There were no competing financial interests in relation to this study.

Ethical approval The University of South Carolina Institutional Review Board provided expedited review and approval of the project, as noted in the Methods section of the manuscript.

\section{References}

Andrade, V. M., Mateus, M. L., Batoreu, M. C., Aschner, M., \& Marreilha dos Santos, A. P. (2015). Lead, arsenic, and manganese metal mixture exposures: Focus on biomarkers of effect. Biological Trace Element Research, 166(1), 13-23. https://doi.org/10.1007/s12011-015-0267-x

Andrade, V. M., Aschner, M., \& Marreilha dos Santos, A. P. (2017). Neurotoxicity of metal mixtures. Advanced Neurobiology., 18, 227-265. https://doi.org/10.1007/978-3319-60189-2_12

Andrew, A. S., Jewell, D. A., Mason, R. A., Whitfield, M. L., Moore, J. H., \& Karagas, M. R. (2008). Drinking-water arsenic exposure modulates gene expression in human lymphocytes from a US population. Environmental Health Perspectives, 116(4), 524-531.

Arita, A., \& Costa, M. (2009). Epigenetics in metal carcinogenesis: Nickel, arsenic, chromium and cadmium. Metallomics, 1(3), 222-228. https://doi.org/10.1039/b903049b

Avgustinova, A., \& Benitah, S. A. (2016). Epigenetic control of adult stem cell function. Nature Reviews Molecular Cell Biology, 17(10), 643-658. https://doi.org/10.1038/nrm. 2016.76

Buniello, A., MacArthur, J. A. L., Cerezo, M., et al. (2019). The NHGRI-EBI GWAS catalog of published genomewide association studies, targeted arrays and summary statistics 2019. Nucleic Acids Research., 47(D1), D1005D1012. https://doi.org/10.1093/nar/gky1120 PMID: 30445434.

Cardenas, A., Rifas-Shiman, S. L., Agha, G., Hivert, M. F., Litonjua, A. A., DeMeo, D. L., Lin, X., Amarasiriwardena, C. J., Oken, E., Gillman, M. W., \& Baccarelli, A. A. (2017). Persistent DNA methylation changes associated with prenatal mercury exposure and cognitive performance during childhood. Science and Reports, 7(1), 288. https://doi.org/10.1038/s41598-017-00384-5

Cobbina, S. J., Chen, Y., Zhou, Z., et al. (2015). Low concentration toxic metal mixture interactions: effects on essential and non-essential metals in brain, liver, and kidneys of mice on sub-chronic exposure. Chemosphere, 132, 79-86. https://doi.org/10.1016/j.chemosphere.2015.03.013

Du, P., Zhang, X., Huang, C. C., Jafari, N., Kibbe, W. A., Hou, L., \& Lin, S. M. (2010). Comparison of Beta-value and $\mathrm{M}$-value methods for quantifying methylation levels by microarray analysis. BMC Bioinformatics, 30(11), 
587. https://doi.org/10.1186/1471-2105-11-587 PMID: 21118553.

U.S. EPA, Office of land and emergency management. Population Surrounding 1,857 Superfund Remedial Sites. 2020. Accessed at: https://www.epa.gov/sites/production/files/ 2015-09/documents/webpopulationrsuperfundsites9.28. 15.pdf

Ferguson-Smith, A. C. (2011). Genomic imprinting: The emergence of an epigenetic paradigm. Nature Reviews Genetics, 12(8), 565-575. https://doi.org/10.1038/nrg3032

Ferreira de Mattos, G., Costa, C., Savio, F., Alonso, M., \& Nicolson, G. L. (2017). Lead poisoning: Acute exposure of the heart to lead ions promotes changes in cardiac function and Cav1 ion channels. Biophysical Reviews., 9(5), 807-825. https://doi.org/10.1007/s12551-017-0303-5

Folmsbee, S. S., Wilcox, D. R., Tyberghein, K., De Bleser, P., Tourtellotte, W. G., van Hengel, J., van Roy, F., \& Gottardi, C. J. (2016). $\alpha$ T-catenin in restricted brain cell types and its potential connection to autism. Journal of Molecular Psychiatry., 21(4), 2. https://doi.org/10.1186/s40303016-0017-9.PMID:27330745;PMCID:PMC4915096

Fortin, J., Triche, T. J., \& Hansen, K. D. (2017). Processing, normalization and integration of the illumina humanmethylationEPIC array with minfi. Bioinformatics. https://doi. org/10.1093/bioinformatics/btw691

Griesi-Oliveira, K., Suzuki, A. M., Alves, A. Y., Mafra, A. C. C. N., Yamamoto, G. L., Ezquina, S., Magalhães, Y. T., Forti, F. L., Sertie, A. L., Zachi, E. C., Vadasz, E., \& Passos-Bueno, M. R. (2018). Actin cytoskeleton dynamics in stem cells from autistic individuals. Science and Reports, 8(1), 11138. https://doi.org/10.1038/s41598-018-29309-6

Heard, E., \& Martienssen, R. A. (2014). Transgenerational epigenetic inheritance: Myths and mechanisms. Cell, 157(1), 95-109. https://doi.org/10.1016/j.cell.2014.02.045

Hua, Z. L., Emiliani, F. E., \& Nathans, J. (2015). Rac1 plays an essential role in axon growth and guidance and in neuronal survival in the central and peripheral nervous systems. Neural Development, 23(10), 21. https://doi.org/10. 1186/s13064-015-0049-3

Iritani, S., Torii, Y., Habuchi, C., Sekiguchi, H., Fujishiro, H., Yoshida, M., Go, Y., Iriki, A., Isoda, M., \& Ozaki, N. (2018). The neuropathological investigation of the brain in a monkey model of autism spectrum disorder with ABCA13 deletion. International Journal of Developmental Neuroscience, 71, 130-139. https://doi.org/10.1016/j. ijdevneu.2018.09.002

Lee, T., Winter, C., Marticke, S. S., Lee, A., \& Luo, L. (2000). Essential roles of drosophila RhoA in the regulation of neuroblast proliferation and dendritic but not axonal morphogenesis. Neuron, 25(2), 307-316. https://doi.org/10. 1016/s0896-6273(00)80896-x

Lessing, D., Anguera, M. C., \& Lee, J. T. (2013). X chromosome inactivation and epigenetic responses to cellular reprogramming. Annual Review of Genomics and Human Genetics, 14, 85-110. https://doi.org/10.1146/annur ev-genom-091212-153530

Liberzon, A., Subramanian, A., Pinchback, R., Thorvaldsdóttir, H., Tamayo, P., \& Mesirov, J. P. (2011). Molecular signatures database (MSigDB) 3.0. Bioinformatics. 27(12), 1739-40. https://doi.org/10.1093/bioinformatics/btr260.
Lin, X., Gu, Y., Zhou, Q., Mao, G., Zou, B., \& Zhao, J. (2016). Combined toxicity of heavy metal mixtures in liver cells. Journal of Applied Toxicology, 36(9), 1163-1172. https:// doi.org/10.1002/jat.3283

Lunyak, V. V., \& Rosenfeld, M. G. (2008). Epigenetic regulation of stem cell fate. Human Molecular Genetics, 17(R1), R28-36. https://doi.org/10.1093/hmg/ddn149

Nazeen, S., Palmer, N. P., Berger, B., \& Kohane, I. S. (2016). Integrative analysis of genetic data sets reveals a shared innate immune component in autism spectrum disorder and its co-morbidities. Genome Biology, 17(1), 228. https://doi.org/10.1186/s13059-016-1084-z

NIEHS, Exposure Science (last reviewed 2021). Retrieved 2021https://www.niehs.nih.gov/health/topics/science/ exposure/index.cfm

Onore, C. E., Nordahl, C. W., Young, G. S., Van de Water, J. A., Rogers, S. J., \& Ashwood, P. (2012). Levels of soluble platelet endothelial cell adhesion molecule-1 and P-selectin are decreased in children with autism spectrum disorder. Biological Psychiatry, 72(12), 10201025. https://doi.org/10.1016/j.biopsych.2012.05.004

Phuapittayalert, L., Saenganantakarn, P., Supanpaiboon, W., Cheunchoojit, S., Hipkaeo, W., \& Sakulsak, N. (2016). Increasing CACNA1C expression in placenta containing high Cd level: An implication of Cd toxicity. Environmental Science and Pollution Research International, 23(24), 24592-24600. https://doi.org/10.1007/ s11356-016-7841-4

Plathe, K., von der Kammer, F., Hassellov, M., et al. (2010). Using FlFFF and aTEM to determine trace metal-nanoparticle associations in riverbed sediment. Environmental Chemistry, 7, 82-93.

Rai, A., Maurya, S. K., Khare, P., Srivastava, A., \& Bandyopadhyay, S. (2010). Characterization of developmental neurotoxicity of $\mathrm{As}, \mathrm{Cd}$, and $\mathrm{Pb}$ mixture: Synergistic action of metal mixture in glial and neuronal functions. Toxicological Sciences., 118(2), 586-601. https://doi.org/ 10.1093/toxsci/kfq266

Rappaport, N., Twik, M., Plaschkes, I., Nudel, R., Iny Stein, T., Levitt, J., Gershoni, M., Morrey, C. P., Safran, M., \& Lancet, D. (2017). MalaCards: An amalgamated human disease compendium with diverse clinical and genetic annotation and structured search. Nucleic Acids Research, 45(D1), D877-D887. https://doi.org/10.1093/nar/gkw10 12 Epub 2016 Nov 28 PMID: 27899610.

Razin, A., \& Cedar, H. (1991). DNA methylation and gene expression. Microbiological Reviews, 55(3), 451-458. PMID: 1943996.

Reichard, J. F., \& Puga, A. (2010). Effects of arsenic exposure on DNA methylation and epigenetic gene regulation. Epigenomics, 2(1), 87-104. https://doi.org/10.2217/epi.09.45

Schecher, W. D., \& McAvoy, D. C. (1992). MINEQL+: A software environment for chemical equilibrium modeling. Computers, Environment and Urban Systems., 16(1), 65-76.

Senut, M. C., Cingolani, P., Sen, A., Kruger, A., Shaik, A., Hirsch, H., Suhr, S. T., \& Ruden, D. (2012). Epigenetics of early-life lead exposure and effects on brain development. Epigenomics, 4(6), 665-674. https://doi.org/10. 2217/epi.12.58 
Skinner, M. K., Guerrero-Bosagna, C., Haque, M., Nilsson, E., Bhandari, R., \& McCarrey, J. R. (2013). Environmentally induced transgenerational epigenetic reprogramming of primordial germ cells and the subsequent germ line. PLoS ONE, 8(7), e66318. https://doi.org/10.1371/journal.pone. 0066318

Skvortsova, K., Iovino, N., \& Bogdanović, O. (2018). Functions and mechanisms of epigenetic inheritance in animals. Nature Reviews Molecular Cell Biology, 19(12), 774-790. https://doi.org/10.1038/s41580-018-0074-2

USEPA. Silver Bow Creek/Butte Area Butte, MT Superfund Site. United States Environmental Protection Agency website. Accessed November 24, 2020. https://cumulis. epa.gov/supercpad/SiteProfiles/index.cfm?fuseaction= second.cleanup\&id $=0800416$

Vassoler, F. M., Byrnes, E. M., \& Pierce, R. C. (2014). The impact of exposure to addictive drugs on future generations: Physiological and behavioral effects. Neuropharmacology, 76, 269-275. https://doi.org/10.1016/j.neuro pharm.2013.06.016
Wolff, G. L., Kodell, R. L., Moore, S. R., \& Cooney, C. A. (1998). Maternal epigenetics and methyl supplements affect agouti gene expression in Avy/a mice. The FASEB Journal, 12(11), 949-957. PMID: 9707167.

Yang, X., Wang, X., Lei, L., Sun, L., Jiao, A., Zhu, K., Xie, T., Liu, H., Zhang, X., Su, Y., Zhang, C., Shi, L., Zhang, D., Zheng, H., Zhang, J., Liu, X., Wang, X., Zhou, X., Sun, C., \& Zhang, B. (2021). Age-related gene alteration in naïve and memory $\mathrm{t}$ cells using precise age-tracking model. Frontiers in Cell Developmental Biology, 11(8), 624380. https://doi.org/10.3389/fcell.2020

Publisher's Note Springer Nature remains neutral with regard to jurisdictional claims in published maps and institutional affiliations. 